\title{
Enthält die Liste des Anhangs der Klauselrichtlinie 93/13/EWG Grundregeln des Europäischen Vertragsrechts?
}

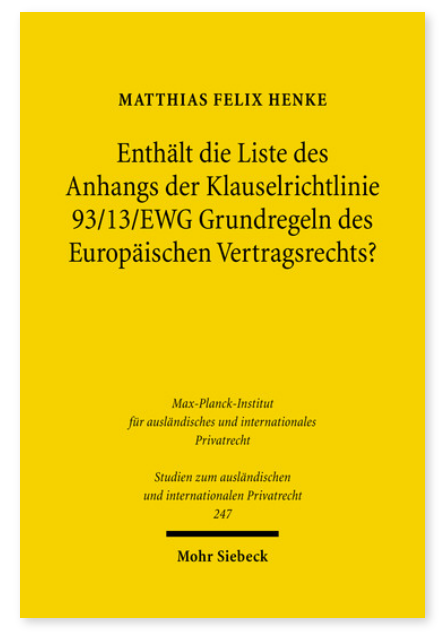

2010. XIX, 209 Seiten. StudIPR 247

ISBN 978-3-16-151432-6

DOI 10.1628/978-3-16-151432-6

eBook PDF 69,00€

ISBN 978-3-16-150360-3

fadengeheftete Broschur $69,00 €$
Zu einer der größten rechtlichen Herausforderungen der kommenden Jahrzehnte gehört die Schaffung eines einheitlichen europäischen Vertragsrechtswerks. Voraussetzung für dessen Akzeptanz sind unter anderem allseits anerkannte vertragsrechtliche Grundregeln. Matthias Felix Henke arbeitet anhand der Liste des Anhangs der Klauselrichtlinie - mit einer eigens dafür entwickelten Methode - einen Grundstock bereits vorhandener europäischer Grundregeln heraus. Diese betreffen schwerpunktmäßig das Zustandekommen eines Vertrags, die Vertragsbindung, die Folgen des Abbruchs von Vertragsverhandlungen, den Anspruch auf Erfüllung, die Vertragsänderung, die Aufrechnung, die Einrede des nicht erfüllten Vertrags sowie die Rechte bei Leistungsstörung. Die herausgearbeiteten Grundregeln können als Ausgangspunkt für weitere einschlägige Forschungen dienen.

Matthias Felix Henke Geboren 1981; 2001-06 Studium der Rechtswissenschaft und Begleitstudium Europarecht in Würzburg, 2006-07 Aufbaustudium Europarecht, 2007 Magister im Europäischen Recht; Rechtsreferendariat im OLG-Bezirk Bamberg; derzeit im Justizdienst des LG-Bezirks Essens.

Jetzt bestellen:

https://mohrsiebeck.com/buch/enthaelt-die-liste-des-anhangs-der-klauselrichtlinie-9313ewg-grundregeln-des-europaeischenvertragsrechts-9783161514326?no_cache=1

order@mohrsiebeck.com

Telefon: +49 (0)7071-923-17

Telefax: $+49(0) 7071-51104$ 